AIm: To investigate whether blood serotonin (5-hydroxytryptamine) (5-HT) modulates musculoskeletal pain differently in seropositive and seronegative rheumatoid arthritis (RA).

Methods: Patients with temporomandibular joint (TMJ) involvement of seropositive RA (33 patients) or seronegative RA (28 patients) and 26 healthy individuals were included. TMJ pain, general musculoskeletal pain, plasma and serum 5-HT, acute phase reactants and thrombocyte count were investigated.

Results: The patients with seropositive $R A$ had higher serum (median $=1130 \mathrm{nmol} / \mathrm{l})$ and plasma $(55 \mathrm{nmol} /$ 1) levels of 5-HT than the healthy individuals (704 nmol $/ 1, p=0.044$ and $23 \mathrm{nmol} / 1, p<0.001$, respectively), and higher plasma levels of 5-HT than the seronegative patients $(14 \mathrm{nmol} / 1, p<0.001)$. There was no significant correlation between serum and plasma levels of 5-HT in any group.

In the seropositive $\mathrm{RA}$ patients, positive correlations were found between serum levels of 5-HT and the number of painful mandibular movements $\left(r_{\mathrm{s}}=\right.$ $0.36, n=33, p=0.042$ ), as well as pain on maximum mouth opening $\left(r_{\mathrm{s}}=0.41, n=24, p=0.047\right)$ and tenderness to digital palpation $\left(r_{\mathrm{s}}=0.49, n=33, p=\right.$ 0.003).

In the healthy individuals, there was a negative correlation between plasma level of 5-HT and the TMJ pressure pain threshold $\left(r_{\mathrm{s}}=-0.47, n=20, p=\right.$ 0.037).

Conclusion: Peripheral serotonergic pain mechanisms seem to be activated by blood 5-HT in patients with seropositive $R A$, in contrast to seronegative patients.

Key words: Arthritis, Healthy, Inflammation, Nociception, Normal, Pain Threshold, Thrombocyte

\section{Blood serotonin and joint pain in seropositive versus seronegative rheumatoid arthritis}

\author{
Sigvard Kopp ${ }^{\mathrm{CA}}$ and Per Alstergren
}

Department of Clinical Oral Physiology, Institute of Odontology, Karolinska Institutet, Box 4064, 14104 Huddinge, Sweden

\footnotetext{
${ }^{\mathrm{CA}}$ Corresponding author

Tel: +4687288281

Fax: +4686080881

E-mail: sigvard.kopp@ofa.ki.se
}

\section{Introduction}

Serotonin (5-hydroxytryptamine) (5-HT) has been shown peripherally to induce plasma extravasation, ${ }^{1,2}$ to modulate vasotonus, ${ }^{3-6}$ and to sensitize or excite nociceptors. ${ }^{7-11}$ Furthermore, 5-HT participates in the peripheral modulation of musculoskeletal pain associated with rheumatoid arthritis (RA). ${ }^{12-16}$

5-HT is produced by enterochromaffin cells in the gastrointestinal mucosa and most of it is immediately absorbed to and stored in the circulating thrombocytes. ${ }^{17}$ The total blood content of 5-HT thus consists of the 5-HT stored in the thrombocytes as well as an unbound plasma fraction, which comprises approximately $5-15 \%$ of the total blood concentration. ${ }^{14,18}$ Thrombocytes from patients with rheumatic diseases have been found to have a lower number of intracellular 5-HT storage organelles compared with thrombocytes from healthy individuals, indicating that the thrombocytes have been activated to release 5-HT. Accordingly, the thrombocyte content of 5-HT is decreased during acute episodes of RA. ${ }^{15}$ Plateletactivating factors such as immune complexes, including the rheumatoid factor, activate thrombocytes to release 5-HT. ${ }^{16,19}$ Presence of the rheumatoid factor in the blood from patients with RA has been associated with high inflammatory activity and poor prognosis with respect to temporomandibular joint (TMJ) involvement ${ }^{20}$, which might partly be explained by thrombocyte activation.

The aim of the present study was therefore to investigate whether musculoskeletal pain including TMJ pain is modulated by serum or plasma $5-\mathrm{HT}$ in patients with RA, and whether there is a difference in this aspect between the seropositive and seronegative forms of the disease. 
Table 1. Gender, age, duration of general and TMJ symptoms as well as number of painful musculoskeletal regions in 33 patients with seropositive RA and 28 patients with seronegative RA involving the TMJ, as well as in 26 healthy individuals

\begin{tabular}{|c|c|c|c|}
\hline Group & Median & IQR & $n$ \\
\hline $\begin{array}{l}\text { Seropositive RA patients } \\
\text { Gender (males/females) }\end{array}$ & & & $\begin{array}{l}33 \\
8 / 25\end{array}$ \\
\hline Age (years) & 52 & 12 & \\
\hline \multicolumn{4}{|l|}{ Duration } \\
\hline General (years) & 12 & 10 & \\
\hline TMJ (years) & 5 & 5 & \\
\hline $\begin{array}{l}\text { Seronegative RA patients } \\
\text { Gender (males/females) }\end{array}$ & & & $\begin{array}{l}28 \\
5 / 23\end{array}$ \\
\hline Age (years) & 44 & 14 & \\
\hline \multicolumn{4}{|l|}{ Duration } \\
\hline General (years) & 12 & 11 & \\
\hline TMJ (years) & 4 & 5 & \\
\hline \multirow{2}{*}{\multicolumn{3}{|c|}{$\begin{array}{l}\text { Healthy individuals } \\
\text { Gender (males/females) }\end{array}$}} & 26 \\
\hline & & & $10 / 16$ \\
\hline Age (years) & 38 & 11 & \\
\hline
\end{tabular}

IQR, Interquartile range; $n$, number of observations.

\section{Materials and methods}

\section{Patients}

This study comprised 13 male and 48 female patients with seropositive (33 patients) or seronegative (28 patients) RA, and was approved by the local Ethical Committee at Huddinge University Hospital (460/99). The examinations and blood samplings were conducted with the understanding and the consent of each subject. The distribution of gender, age and duration of general as well as temporomandibular symptoms is presented in Table 1 . The patients were referred to the Department of Clinical Oral Physiology from medical practitioners due to TMJ involvement of RA. The inclusion criteria for this study were diagnosis of RA according to the 1987 diagnostic criteria by the American College of Rheumatology, ${ }^{21}$ as well as TMJ arthritis according to the diagnostic classification by the American Academy of Orofacial Pain. ${ }^{22}$ The patients had not been subjected to any recent $(<3$ month) specific treatment of local pain in the TMJ. Patients whose symptoms could be referred to disease in other components of the temporomandibular system (e.g. toothache, myalgia or neuralgia), or local infection of the skin over the TMJ were excluded.

Regarding ongoing medication, 12 of the seropositive patients and four of the seronegative patients used glucocorticoids, 17 of the seropositive patients and five of the seronegative patients used disease-modifying anti-rheumatic drugs, and 21 of the seropositive patients and 10 of the seronegative patients used non-steriodal anti-inflammatory drugs. Of the seropositive patients, six patients did not use any medication, and the corresponding figure for the seronegative patients was 15 patients. More seropositive patients used disease-modifying anti-rheu- matic drugs than the seropositive patients $(p=0.014)$, while less seropositive patients used no medication compared with the seronegative patients $(p=$ 0.009).

The patients were divided into two groups with respect to presence (seropositive) or absence (seronegative) of rheumatoid factor in serum.

\section{Healthy individuals}

For comparison, a group of 10 male and 16 female healthy individuals was included in the study (Table 1). The healthy individuals had no history of or clinical signs of ongoing temporomandibular disorder or pain.

The conduct of this study was approved by the ethical committee at Huddinge University Hospital (310/97).

\section{Blood sampling}

Venous blood was collected from the patients in a sodium citrate tube $(0.105 \mathrm{~mol} / \mathrm{l})$ for measurement of the erythrocyte sedimentation rate and the thrombocyte particle concentration in the blood. Another sample was obtained in an ethylenediamine tetraacetic acid tube that was immediately cooled and centrifugated $\left(1500 \times g\right.$ for $30 \mathrm{~min}$ at $\left.4^{\circ} \mathrm{C}\right)$. The upper third of the supernatant (i.e. platelet-poor plasma) was obtained, frozen $\left(-70^{\circ} \mathrm{C}\right)$ and later examined for the platelet-poor plasma level of 5-HT. In addition, venous blood was collected without additives for analysis of the serum level of 5-HT, rheumatoid factor and C-reactive protein. These tubes were left at room 
Table 2. Median, interquartile range (IQR), number of observations ( $n$ ) and percent observations exceeding 0 (\% positive) regarding clinical and blood variables in 33 patients with seropositive RA, 28 patients with seronegative RA and 26 healthy individuals

\begin{tabular}{|c|c|c|c|c|c|c|c|c|c|c|c|c|}
\hline \multirow[t]{3}{*}{ Variable } & \multicolumn{8}{|c|}{ Patients } & & & & \\
\hline & \multicolumn{4}{|c|}{ Seropositive RA } & \multicolumn{4}{|c|}{ Seronegative RA } & \multicolumn{4}{|c|}{ Healthy individuals } \\
\hline & Median & IQR & $n$ & $\%$ positive & Median & IQR & $n$ & $\%$ positive & Median & IQR & $n$ & $\%$ positive \\
\hline $\begin{array}{l}\text { Number of painful joint } \\
\text { regions }(0-9)\end{array}$ & 5 & 4 & 33 & 100 & 3 & 3 & 28 & 96 & 0 & 0 & 26 & 0 \\
\hline $\begin{array}{l}\text { General joint pain intensity } \\
\text { (VAS) }\end{array}$ & 60 & 36 & 23 & 96 & 37 & 31 & 23 & 91 & 0 & 0 & 26 & 0 \\
\hline $\begin{array}{l}\text { Pressure pain threshold, } \\
\text { reference site }(\mathrm{kPa})\end{array}$ & 267 & 181 & 18 & 100 & 224 & 125 & 22 & 100 & 313 & 120 & 19 & 100 \\
\hline $\begin{array}{l}\text { Serum level of serotonin } \\
(\mathrm{nmol} / \mathrm{l})\end{array}$ & 1130 & 692 & 33 & 100 & 919 & 799 & 28 & 100 & 704 & 519 & 26 & 100 \\
\hline $\begin{array}{l}\text { Plasma level of serotonin } \\
\text { (nmol/l) }\end{array}$ & 55 & 41 & 21 & 100 & 14 & 20 & 22 & 100 & 23 & 19 & 20 & 100 \\
\hline $\begin{array}{l}\text { Erythrocyte sedimentation rate } \\
(\mathrm{mm} / \mathrm{h})\end{array}$ & 32 & 25 & 29 & 100 & 14 & 18 & 27 & 100 & n.a. & & & \\
\hline C-reactive protein (mg/l) & 11 & 24 & 30 & 60 & 0 & 6 & 27 & 41 & 0 & 0 & 15 & 5 \\
\hline $\begin{array}{l}\text { Thrombocyte particle count }(\times \\
\left.10^{9} / I\right)\end{array}$ & 350 & 73 & 26 & 100 & 292 & 70 & 26 & 100 & 266 & 60 & 15 & 100 \\
\hline Rheumatoid factor (IU) & 48 & 154 & 31 & 77 & 0 & 0 & 27 & 0 & n.a. & & & \\
\hline TMJ pain intensity (VAS) & 50 & 52 & 33 & 85 & 68 & 29 & 26 & 100 & 0 & 0 & 26 & 4 \\
\hline $\begin{array}{l}\text { Pressure pain threshold of the } \\
\text { TMJ (kPa) }\end{array}$ & 324 & 113 & 33 & 100 & 324 & 152 & 26 & 100 & 414 & 146 & 20 & 100 \\
\hline $\begin{array}{l}\text { Tenderness to digital palpation } \\
\text { of the TMJ }(0-8)\end{array}$ & 2 & 2 & 33 & 97 & 2 & 2 & 28 & 89 & 0 & 0 & 26 & 12 \\
\hline $\begin{array}{l}\text { Pain intensity on maximum } \\
\text { mouth opening (VAS) }\end{array}$ & 51 & 68 & 24 & 75 & 71 & 31 & 23 & 96 & 0 & 0 & 24 & 13 \\
\hline $\begin{array}{l}\text { Number of painful mandibular } \\
\text { movements }(0-4)\end{array}$ & 3 & 2 & 33 & 88 & 5 & 2 & 28 & 96 & 0 & 0 & 26 & 19 \\
\hline
\end{tabular}

n.a., Not applicable.

temperature for $60 \mathrm{~min}$ to coagulate and thereafter centrifuged $\left(1500 \times g\right.$ for $10 \mathrm{~min}$ at $\left.+4^{\circ} \mathrm{C}\right)$. The rheumatoid factor concentration was analyzed with the routine procedure (nephalometry) at the department of Clinical Immunology, Huddinge University Hospital and measured in international units per millilitre (IU/ml). C-reactive protein was analyzed with Tina-quant ${ }^{\circledR}$ CRP, an immunoturbidimetric assay; precision of the assay: intra-assay and inter-assay coefficient of variation $<7 \%$, and the detection limit $3 \mathrm{mg} / \mathrm{l}$ (Roche, Basel, Switzerland). C-reactive protein values below $10 \mathrm{mg} / \mathrm{l}$ and concentrations of rheumatoid factor below $15 \mathrm{IU} / \mathrm{ml}$ were considered as zero values. The remaining serum was then frozen $\left(-20^{\circ} \mathrm{C}\right)$ until analysis of 5-HT. Blood samples from the healthy individuals were obtained as already described and analyzed for plasma and serum levels of 5-HT as well as thrombocyte particle concentration.

\section{Assessment of subjective symptoms and clinical signs}

The patients were asked about current pain in nine joint regions besides the TMJ region (neck, shoulders, elbows, hands, upper back, lower back, hips, knees and feet) and the number of painful regions was recorded (score $=0-9$ ). A $100 \mathrm{~mm}$ visual analogue scale (VAS) (ACO, Stockholm, Sweden) with endpoints marked with 'No pain' (score 0) and 'Worst pain ever experienced' (score $=0-100$ ) was used to assess the current resting pain intensity experienced in the TMJ region and the joint pain in general. A score of tenderness to digital palpation of the TMJ was adopted that comprised tenderness of the lateral and posterior aspect of the joint. On each side and location (lateral and posterior), one unit was scored if the patient reported tenderness and two units if the palpation caused a pain reflex (score per joint $=0-4$ ). The pressure pain threshold to linearly increasing pressure over the lateral aspect of the TMJ as well as over a reference site, glabella on the frontal bone, was assessed with an electronic algometer (Somedic Sales $\mathrm{AB}$, Sollentuna, Sweden) with a $1 \mathrm{~cm}^{2}$ blunt rubber tip and a pressure rate of $50 \mathrm{kPa} / \mathrm{s}$. The number of different mandibular movements provoking TMJ pain, including maximum mouth opening, laterotrusion to both sides and protrusion, was counted on each side (score $=0-4)$. Pain on maximum mouth opening was also recorded on a 100-mm VAS. 

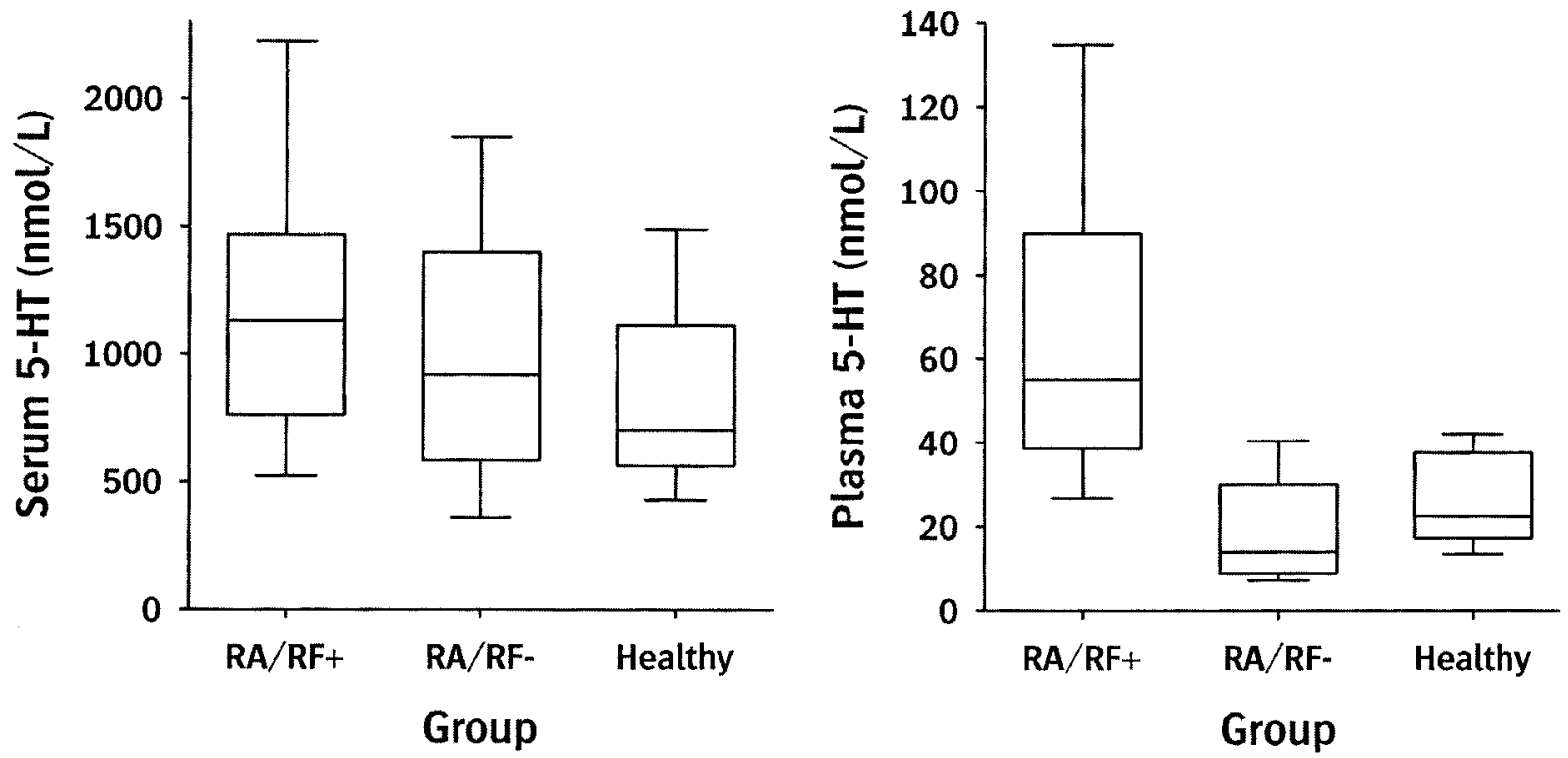

FIG. 1. Box plot showing serum and plasma levels of $5-\mathrm{HT}$ in 33 patients with seropositive rheumatoid arthritis (RA/RF+), 28 patients with seronegative RA (RA/RF-) and 26 healthy individuals. The seropositive patients had higher serum and plasma levels of $5-\mathrm{HT}$ than the healthy individuals $(p=0.044$ and $p<0.001$, respectively).

\section{Analysis of serotonin}

Serotonin was analyzed in duplicate by a commercially available enzyme immunoassay kit $\mathrm{Nr} 0642$; Immunotech International, Germany) with a detection limit and sensitivity of $0.5 \mathrm{nmol} / \mathrm{l}$. The intra-assay coefficient of variation is reported by the manufacturer to be less than $9.4 \%$, and the inter-assay coefficient of variation less than $9.9 \%$. The serum 5-HT samples were diluted 1:20 prior to analysis and the values obtained were corrected for the dilution.

\section{Statistics}

When joint-related variables were correlated to variables related to the individual, the sum of the left and right side was used. Non-parametric statistical methods were used including median and interquartile range ( 75 th percentile-25th percentile) for descriptive statistics. The significance of differences in distribution of medication between the seropositive and seronegative patients was tested with the $\chi^{2}$-test. The significance of the differences between the three groups was tested with the one-way analysis of variance on ranks with Dunn's multiple comparison post-boc test. Spearman's ranked correlation test was used to test the significance of the correlations. A probability level of $p<0.05$ was considered significant.

\section{Results}

Table 2 presents the clinical and blood variables for the patient groups as well as for the healthy individuals.

\section{Serotonin concentrations}

The patients with seropositive RA had higher serum and plasma levels of 5-HT than the healthy individuals $(p=0.044$ and $p<0.001$, respectively; Fig. 1$)$ and higher plasma levels of 5-HT than the seronegative patients $(\phi<0.001$; Fig. 1) when all groups were compared. The highest plasma and serum levels were found in the patients with seropositive RA: 218 and $3530 \mathrm{nmol} / \mathrm{l}$, respectively.

There was no significant correlation between serum and plasma levels of 5-HT in any group. In addition, there were no differences in serum or plasma levels of 5-HT between patients that used medication with glucocorticoid, disease-modifying anti-rheumatic drugs or non-steriodal anti-inflammatory drugs and those patients who did not use these medications.

\section{Serotonin and pain}

In the seropositive RA patients, positive correlations were found between serum levels of 5-HT and the number of painful mandibular movements $\left(r_{\mathrm{s}}=0.36\right.$, $n=33, p=0.042$ ), as well as pain on maximum mouth opening ( $r_{\mathrm{s}}=0.41, n=24, p=0.047$; Fig. 2$)$ and tenderness to digital palpation $\left(r_{\mathrm{s}}=0.49, n=33\right.$, $p=0.003$ ).

In the healthy individuals, there was a negative correlation between the plasma level of 5-HT and the TMJ pressure pain threshold $\left(r_{\mathrm{s}}=-0.47, n=20\right.$, $p=0.037$; Fig. 3). 


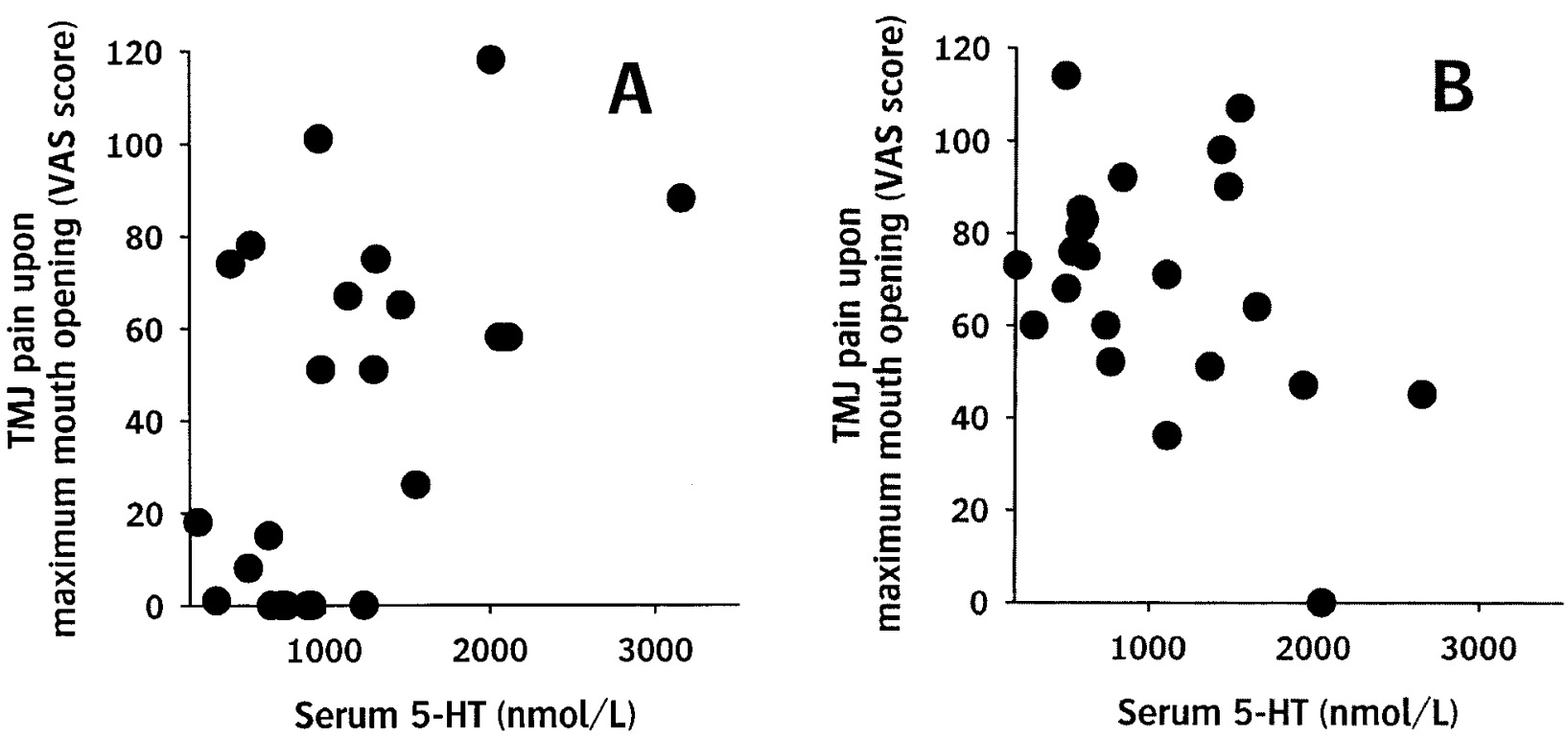

FIG. 2. Scatter plot showing the relation between the serum level of $5-H T$ and TMJ pain intensity, as assessed with a VAS $(0-100 \mathrm{~mm})$, experienced on maximum mouth opening in patients with $(\mathrm{A})$ seropositive $\mathrm{RA}\left(r_{\mathrm{s}}=0.41, n=24, p=0.047\right)$ and $(\mathrm{B})$ seronegative RA $\left(r_{\mathrm{s}}=-0.27, n=23, p=0.214\right)$

\section{Group differences}

The seropositive RA patients had a higher number of joint regions involved with the disease $(p=0.004)$ and a higher degree of general joint pain $(p=0.006)$ compared with the seronegative patients. On the contrary, the seronegative patients showed a higher degree of TMJ resting pain $(\phi=0.049)$, pain on maximum mouth opening $(\phi=0.015)$ and a higher number of painful TMJ movements $(p<0.001)$ than the seropositive patients. The seropositive patients had a significantly higher erythrocyte sedimentation rate $(p<0.001)$, thrombocyte particle count $(p=$ $0.009)$ and C-reactive protein $(p<0.001)$ than the seronegative patients.

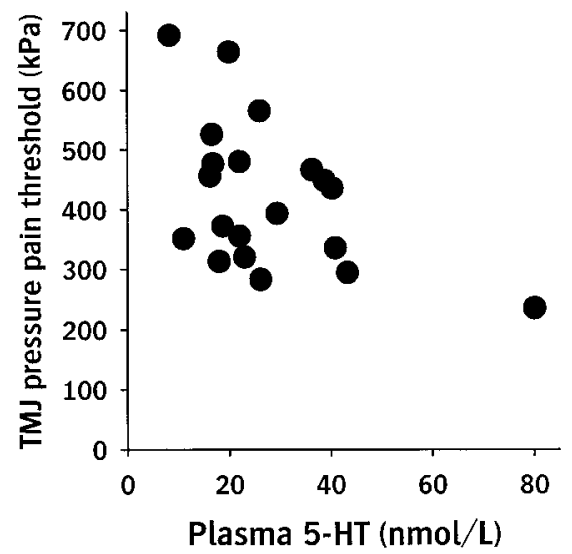

FIG. 3. The relation between the plasma level of 5-HT and the sum of pressure pain thresholds over the lateral aspects of the right and left temporomandibular joints in 20 healthy individuals $\left(r_{\mathrm{s}}=-0.47, n=20, p=0.037\right)$.
There was a positive correlation between serum level of 5-HT and thrombocyte particle count in the seropositive $\left(r_{\mathrm{s}}=0.42, n=26, p=0.031\right)$ and seronegative patients $\left(r_{\mathrm{s}}=0.48, n=26, p=0.013\right)$.

When all three groups were compared, the patients with seronegative RA had lower TMJ and reference site pressure pain thresholds than the healthy individuals $(p=0.020$ and $p=0.039$, respectively).

\section{Discussion}

The present study shows that high serum concentration of 5-HT is associated with TMJ pain and palpatory tenderness in patients with TMJ arthritis due to seropositive RA. These patients had elevated serum and plasma concentrations of 5-HT and a higher inflammatory activity than the patients with seronegative RA.

Regarding the patients with seropositive RA, these findings are in agreement with a previous study where a high serum level of 5-HT was found to be associated with pain during mandibular movements in RA patients. ${ }^{23}$ However, this relationship seems to be confined to seropositive RA, according to the results in the present study. The high total blood content of 5-HT in this group seems to influence nociception within the TMJ, suggesting that serum 5-HT is involved in the modulation of inflammation and joint pain in seropositive patients.

Thrombocytes are supposed to be the major source of 5-HT in the blood. A high thrombocyte particle count was associated with high serum level of 5-HT in both groups of patients, supporting this condition in 
RA patients. In the seropositive patients, thrombocytes were present in higher numbers than in the seronegative patients. The thrombocyte count is increased during periods of high general inflammatory activity, although it was not significantly correlated with erythrocyte sedimentation rate or C-reactive protein in this study. However, the seropositive patients had higher general inflammatory activity, according to the erythrocyte sedimentation rate and $\mathrm{C}$-reactive protein level as well as the more pronounced general clinical signs, than the seronegative patients, which thus may explain the higher serum 5-HT level in these patients.

The thrombocytes may become activated during inflammation by platelet-activating factors such as the rheumatoid factor to release 5-HT, which increases plasma and thereby also tissue 5-HT levels. ${ }^{12,15}$ Presence of the rheumatoid factor in the blood of patients with RA has been found to be associated with poor prognosis and higher disease activity with respect to the $\mathrm{TMJ},{ }^{20}$ and patients with seropositive RA generally present more pronounced TMJ symptoms, ${ }^{24,25}$ which was also the fact in the present study. The lack of significant correlation between the plasma level of 5-HT and the thrombocyte particle count in our study indicates that other sources of 5-HT (e.g. mast cells) contribute to the plasma level or that there is a large variation in the degree of thrombocyte activation in these patients. The variation in titer of the platelet-activating rheumatoid factor ${ }^{16,19}$ in the seropositive patients may explain the latter condition. Nevertheless, our findings show that the plasma level of 5-HT is abnormally high in seropositive patients but not in seronegative patients.

An increased plasma level of 5-HT would probably cause an immediate increase of the tissue 5-HT level, resulting in enhanced stimulation of peripheral 5-HT receptors. In turn, this may sensitize nociceptors and cause pain, hyperalgesia or allodynia.,8,10 The seropositive group showed elevated serum and plasma levels of 5-HT as well as elevated general disease activity. 5-HT may therefore be one factor in the modulation of general hyperalgesia/allodynia in patients with seropositive RA, although no direct association between 5-HT levels and pressure pain threshold over the reference site was found in the present study.

The present study shows differences between patients with seropositive and seronegative RA concerning inflammatory activity and contribution of serotonergic mechanism to TMJ pain. Peripheral serotonergic pain mechanisms do not seem to be important in the seronegative patients, while these mechanisms seem to influence pain in the seropositive patients. As previously discussed, one reason for this difference can be a higher degree of thrombocyte activation in the seropositive patients.
Another explanation could be differences in 5-HT receptor expression on nociceptors and blood vessels.

The association between high plasma level of 5-HT and low pressure pain threshold over the TMJ in the healthy individuals is remarkable, since it indicates that unbound 5-HT in the blood is able to sensitize peripheral nociceptors for mechanical stimulation. This is in concordance with a previous study where high plasma 5-HT was associated with low pressure pain threshold over the masseter muscle. ${ }^{14}$ In addition, injection of 5-HT into the masseter muscle of healthy individuals causes more local pain and a larger decrease in local pressure pain thresholds than does injection of saline. ${ }^{26}$ 5-HT may thus be one determinant of TMJ pressure pain threshold in healthy individuals, which strengthens the assumption that the plasma level of 5-HT has a role in physiological nociception. The difference between patients and healthy individuals with respect to this relation could be due to a difference in the 5-HT receptor population on the nociceptors. ${ }^{17}$

In conclusion, the present study indicates that peripheral serotonergic pain mechanisms are activated by blood 5-HT in patients with seropositive RA, in contrast to seronegative RA patients.

ACKNOWLEDGEMENTS. The authors would like to express their gratitude to their dental assistant Ebba Lagerkrans for excellent work and to the volunteers who participated in this study. This study was financially supported by grants from the Swedish Medical Research Council (grant 10416), the Institute of Odontology, Karolinska Institutet, the Swedish National Association against Rheumatism, Signe and Reihold Sund's Foundation, and the Swedish Dental Association.

\section{References}

1. Herbert MK, Schmidt RF. Activation of normal and inflamed fine articular afferent units by serotonin. Pain 1992; 50: 79-88.

2. Pierce PA, Xie GX, Peroutka SJ, Green PG, Levine JD. 5-Hydroxytryptamine-induced synovial plasma extravasation is mediated via 5-hydroxytryptamine $2 \mathrm{~A}$ receptors on sympathetic efferent terminals. $J$ Pharmacol Exp Ther 1995; 275: 502-508.

3. Bruning TA, Chang PC, Blauw GJ, Vermeij P, van Zwieten PA. Serotonininduced vasodilatation in the human forearm is mediated by the 'nitric oxide-pathway': no evidence for involvement of the 5-HT3-receptor. $J$ Cardiovasc Pharmacol 1993; 22: 44-51.

4. Jansen I, Olesen J, Edvinsson L. 5-Hydroxytryptamine receptor character ization of human cerebral, middle meningeal and temporal arteries regional differences. Acta Physiol Scand 1993; 147: 141-150.

5. Wiernsperger NF. Serotonin, 5-HT2 receptors, and their blockade by naftidrofuryl: a targeted therapy of vascular diseases. J Cardiovasc Pharmacol 1994; 23 (Suppl 3): S37-S43.

6. Frishman WH, Huberfeld S, Okin S, Wang YH, Kumar A, Shareef B. Serotonin and serotonin antagonism in cardiovascular and non-cardiovascular disease. J Clin Pharmacol 1995; 35: 541-572.

7. Richardson BP, Engel G. The pharmacology and function of 5-HT3 receptors. Trends Neurosci 1986; 9: 424-428.

8. Grubb BD, McQueen DS, Iggo A, Birrell GJ, Dutia MB. A study of 5-HTreceptors associated with afferent nerves located in normal and inflamed rat ankle joints. Agents Actions 1988; 25: 216-218.

9. Giordano J, Rogers LV. Peripherally administered serotonin 5-HT3 receptor antagonists reduce inflammatory pain in rats. Eur J Pharmacol 1989; 170: 83-86.

10. Birrell GJ, McQueen DS, Iggo A, Grubb BD. The effects of 5-HT on articular sensory receptors in normal and arthritic rats. Br J Pharmacol 1990; 101: 715-721

11. Taiwo YO, Levine JD. Serotonin is a directly-acting hyperalgesic agent in the rat. Neuroscience 1992; 48: 485-490.

12. Endresen GK. Evidence for activation of platelets in the synovial fluid from patients with rheumatoid arthritis. Rbeumatol Int 1989; 9: $19-24$ 
13. Alstergren P, Kopp S. Pain and synovial fluid concentration of serotonin in arthritic temporomandibular joints. Pain 1997; 72: 137-143

14. Ernberg M, Voog Ü, Alstergren P, Lundeberg T, Kopp S. Plasma and serum serotonin levels and their relationship to orofacial pain and anxiety in fibromyalgia. J Orofacial Pain 2000; 14: 37-46.

15. Zeller J, Weissbarth E, Baruth B, Mielke H, Deicher H. Serotonin content of platelets in inflammatory rheumatic diseases. Correlation with clinical activity. Arthritis Rbeum 1983; 26: 532-540.

16. Cunningham TJ, Medcalf RL, Mathews JD, Muirden KD. Platelet releasing activity in sera of patients with rheumatoid vasculitis. Ann Rbeum Dis 1986; 45: 15-20

17. Gyermek L. Pharmacology of serotonin as related to anesthesia. J Clin Anesth 1996; 8: 402-425.

18. Chauveau J, Fert V, Morel AM, Delaage MA. Rapid and specific enzyme immunoassay of serotonin. Clin Chem 1991; 37: 1178-1184.

19. Valone FH, Austen KF, Goetzl EJ. Identification of the platelet activating activity in rheumatoid synovial fluid as an intermediate molecular weight complex of IgG. J Immunol 1979; 122: 703-709.

20. Tegelberg A, Kopp S, Huddenius K, Forssman L. Relationship between disorder in the stomatognathic system and general joint involvement in individuals with rheumatoid arthritis. Acta Odontol Scand 1987; 45: 391-398.

21. Arnett FC, Edworthy SM, Bloch DA, et al The American Rheumatism Association 1987 revised criteria for the classification of rheumatoid arthritis. Arthritis Rbeum 1988; 31: 315-324.
22. Okeson JP. Differential diagnosis and management considerations if temporomandibular disorders. In Okeson JP, ed. Orofacial Pain Guidelines for Assessment, Diagnosis and Management. Carol Stream Quintessence, 1996; pp. 113-184.

23. Alstergren P, Ernberg M, Kopp S, Lundeberg T, Theodorsson E. TMJ pain in relation to circulating neuropeptide $\mathrm{Y}$, serotonin, and interleukin-1 beta in rheumatoid arthritis. J Orofacial Pain 1999; 13: 49-55.

24. Tegelberg A, Kopp S. Clinical findings in the stomatognathic system for individuals with rheumatoid arthritis and osteoarthrosis. Acta Odontol Scand 1987; 45: 65-75.

25. Tegelberg A, Kopp S. Subjective symptoms from the stomatognathic system in individuals with rheumatoid arthritis and osteoarthrosis. Swed Dent J 1987; 11: 11-22.

26. Ernberg M. Pain and allodynia/hyperalgesia induced by intramuscular injection of serotonin in patients with fibromyalgia and healthy individuals. Pain 2000; 85: 31-39.

Received 22 March 2002

Accepted 22 April 2002 


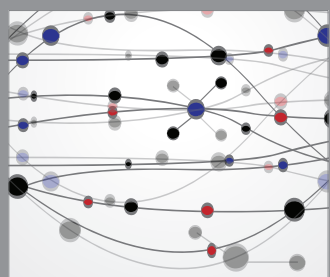

The Scientific World Journal
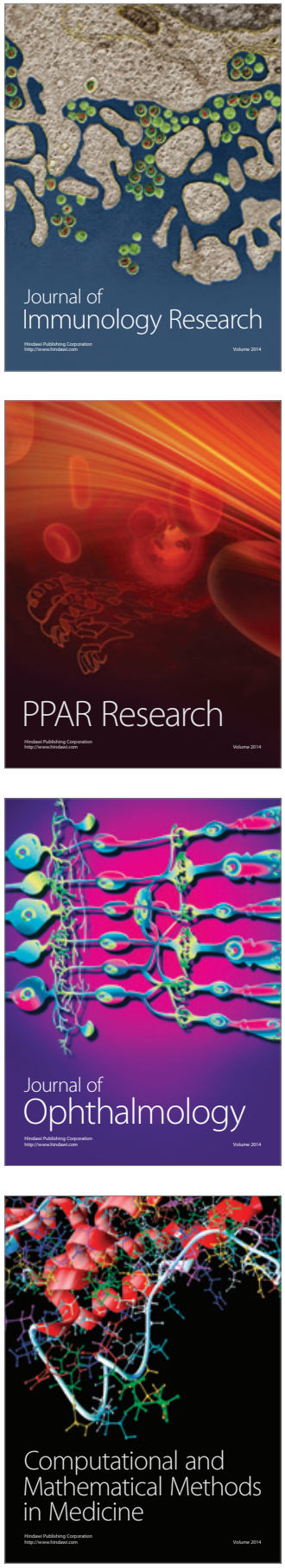

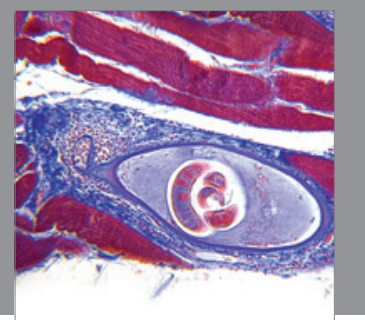

Gastroenterology

Research and Practice
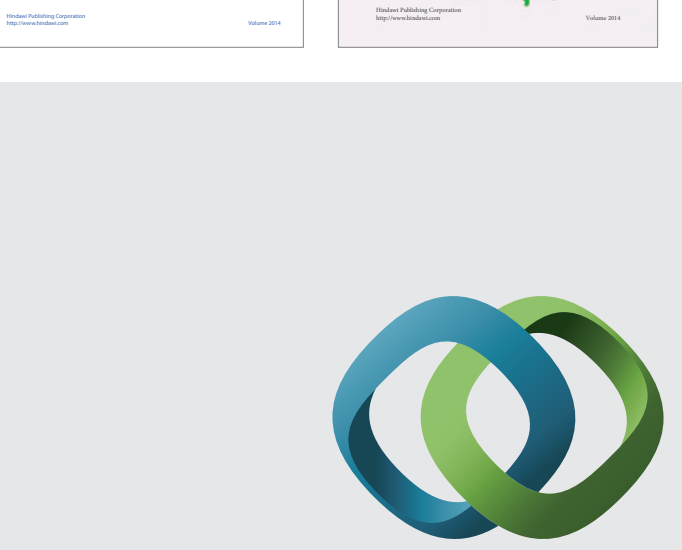

\section{Hindawi}

Submit your manuscripts at

http://www.hindawi.com
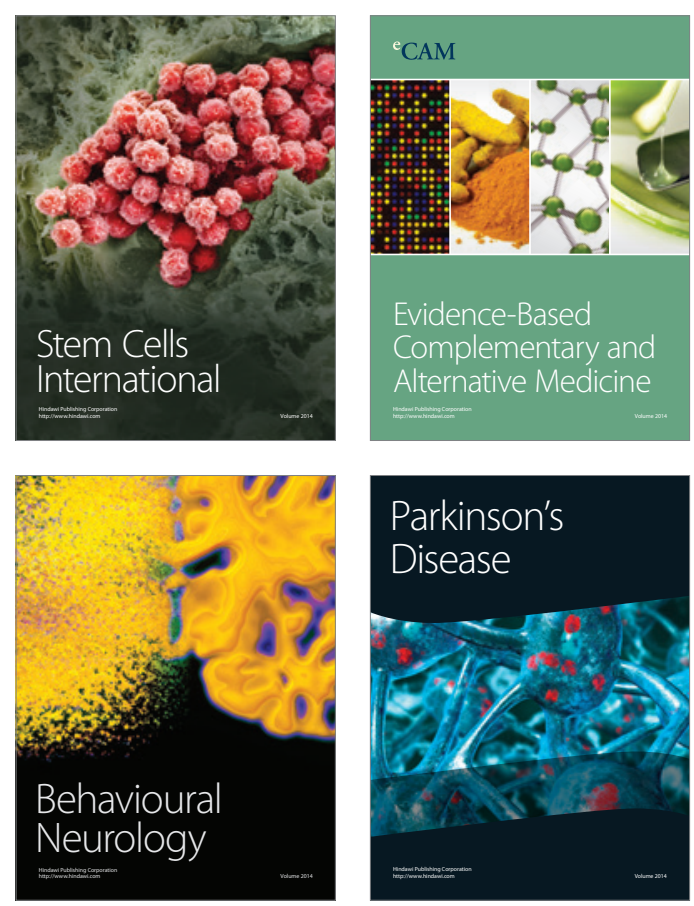

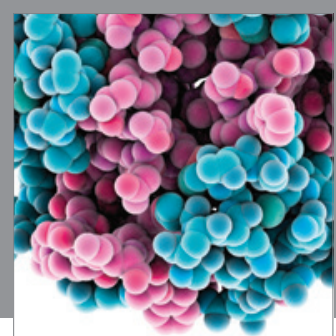

Journal of
Diabetes Research

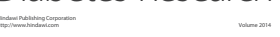

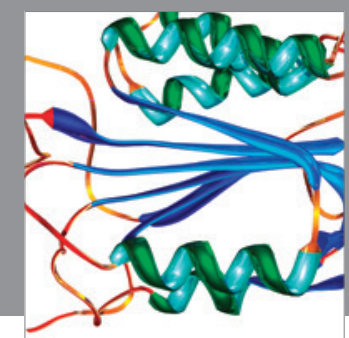

Disease Markers
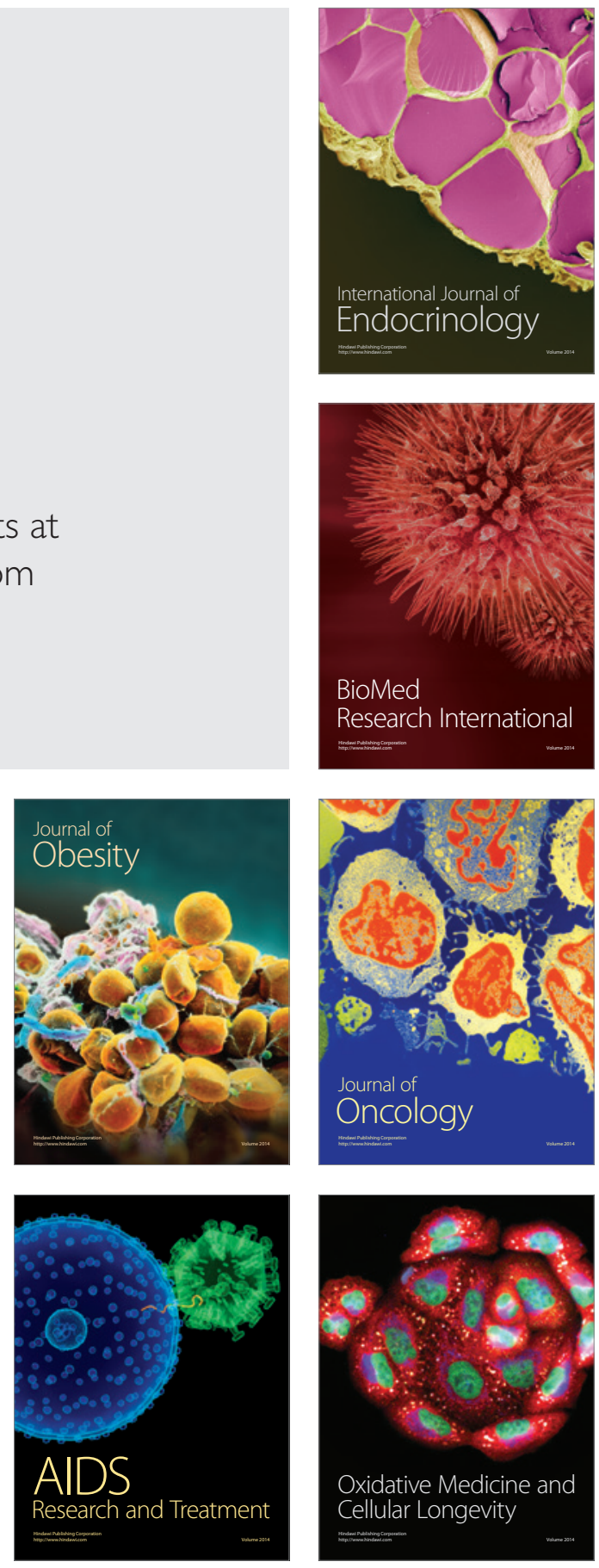